Original Article

\title{
EVALUATION HYPOLIPIDEMIC ACTIVITY OF AROGYAVARDHINI AND ZPTER TABLET IN CHOLESTEROL-RICH HIGH FAT DIET (HFD) INDUCED HYPERLIPIDEMIA IN WISTAR RATS
}

\author{
DINESH D. GHADIGAONKAR ${ }^{*}$, MUKESH B. CHAWDA², KAPIL S. THAKUR ${ }^{3}$, PAWAN K. KUSHWAH ${ }^{1}$
}

${ }^{1}$ Division of Biomedical Services, Shree Dhootapapeshwar Ltd., Panvel, Maharashtra, 2Solumiks Herbaceuticals Ltd., Mumbai, Maharashtra, ${ }^{3}$ Quality Control Department, Shree Dhootapapeshwar Ltd., Panvel, Maharashtra

Email: ghadigaonkar.d@gmail.com

Received: 15 Nov 2018 Revised and Accepted: 16 Apr 2019

\section{ABSTRACT}

Objective: The present research work aims to evaluate the hypolipidemic activity of arogyavardhini and zpter tablet in high fat diet (HFD) induced hyperlipidemia in wistar rats.

Methods: Wistar rats were divided in 5 groups. The normal control group received standard pellet diet. The HFD group received HFD rich in cholesterol. The HFD+Arogyavardhini group received HFD rich in cholesterol along with Arogyavardhini treatment. The HFD+zpter group received HFD rich in cholesterol along with zpter treatment. The standard Control group received HFD rich in cholesterol and treatment with Atorvastatin. Serum Lipid profile estimation and histopathological estimations done at end treatment. Group means were compared with Analysis of Variance (ANOVA) followed by Tukey's post-hoc analysis $(\mathrm{P}<0.05)$.

Result: HFD group shows significant $(\mathrm{P}<0.05)$ increase in total cholesterol (TC) levels $(207.15 \mathrm{mg} / \mathrm{dl})$ and triglyceride $(\mathrm{TG})$ levels $(223.83 \mathrm{mg} / \mathrm{dl})$ when compared with standard pellet fed rats $(\mathrm{TC}=151.05 \mathrm{mg} / \mathrm{dl}$ and $\mathrm{TG}=164.67 \mathrm{mg} / \mathrm{dl})$. Treatment with Arogyavardhini significantly $(\mathrm{P}<0.05)$ reduces the increased levels of TC $(160.123 \mathrm{mg} / \mathrm{dl})$ and TG $(189.5 \mathrm{mg} / \mathrm{dl})$ in hyperlipedimic rats. Treatment with Zpter significantly $(\mathrm{P}<0.05)$ reduces the increased levels of TC $(163.89 \mathrm{mg} / \mathrm{dl})$ and TG $(193.167 \mathrm{mg} / \mathrm{dl})$ in hyperlipedimic rats, which is comparable to standard treatment atorvastatin $(\mathrm{TC}=155.81 \mathrm{mg} / \mathrm{dl}, \mathrm{TG}=180.33 \mathrm{mg} / \mathrm{dl})$.

Conclusion: The observations in this study suggest that, herbal formulations arogyavardhini and zpter have the potential to overcome hyperlipidemia.

Keywords: Ayurveda, Hyperlipidemia, Arogyavardhini, Zpter, Wistar Rats

(C) 2019 The Authors. Published by Innovare Academic Sciences Pvt Ltd. This is an open access article under the CC BY license (http://creativecommons.org/licenses/by/4.0/) DOI: http://dx.doi.org/10.22159/ijpps.2019v11i6.30805

\section{INTRODUCTION}

Hyperlipidemia is an illness, impairing the body in an unnoticeable way which is characterized by increased blood levels of lipids (fats) specifically cholesterol, cholesterol esters, phospholipids, plasma lipoproteins, low density lipoprotein (LDL) and it reduces highdensity lipoproteins (HDL). Hyperlipidemia hastens systemic atherosclerosis, which is considered as a major risk factor for causing atherosclerotic cardiovascular disease (ASCVD), like stroke, coronary artery disease, myocardial infarction and ischemic cardiomyopathy [1-4].

ASCVD is associated with major morbidity and mortality throughout the globe. Numerous reports indicate that there is a direct correlation exist between increased serum LDL and increased risk of cardiovascular diseases [5]. Several studies have reported that cholesterol-rich LDL and other apolipoproteins, like very lowdensity lipoproteins (VLDL) and its intermediate forms like intermediate density lipoproteins (IDL) has a major role in the development of ASCVD [6]

Cholesterol, a greasy substance, the main constituent of steroid hormones, bile salts and vitamin D. It is a constituent of cell membranes as well. It is both derived from the diet and synthesized within the body, specifically in the liver [7]. Raised serum cholesterol level predisposes to the risk of heart disease and stroke. Universally, a third of ischemic heart diseases are due to high cholesterol level. In general, increased cholesterol is responsible to cause 2.6 million deaths ( $4.5 \%$ of total) and 29.7 million disability adjusted life years (DALYS), or $2.0 \%$ of total DALYS. There is a positive correlation between increased total cholesterol and ischemic heart disease in the developed and developing world [8].
Ayurved, 5,000-year-old system of medication is a holistic healing system that regards every individual as distinctive, and additionally takes under consideration the inherent relationship between the universe and individual. The aim of ayurveda medicine is to balance Tri-dosha (Vata, Pitta, and Kapha), the basic functional elements of the body to maintain the state of health and prevent illness through diet, nutrition, herbs, external therapies, meditation and daily and seasonal code of conduct or routines $[9,10]$

There is no particular terminology for hyperlipidemia within the Ayurved. There are reports indicating the use of distinct terminology for hyperlipidemia, e. g. Rasagata Sneha Vriddhi (increase in lipids in plasma), Rasa-Raktagata Sneha Vriddhi (increase in the lipids in plasma and blood), Medovriddhi (generalized lipid increase) Medoroga or Medodosha (obesity), AAMA Medo Dhatu (ill-formed adipose tissue). Hyperlipidemia condition reflects its closeness to Asthayi Medo Dhatu Vriddhi (abnormal increase in circulating lipids). This overly raised lipids in circulation are AAMA in nature, resulting in further complexity $[10,11]$. The abnormal MEDA (fats) developed because of an aberrant state of metabolite circulates within the body which gets accumulated, in turn manifested by flabbiness of the body parts like breasts, abdomen, etc. It causes hindrance to the flow of lymph and blood, inflicting lethargy, difficulty breathing, excess sleep, excessive perspiration, a foul body odor, and weakness, lack of stamina and loss of libido. Eventually, the surplus of fats progressively involved in DOSHA in the body and responsible for disorders such as hypercholesterolemia, hypertension, diabetes mellitus, heart problems, joint disorders, and obesity.

Recent hyperlipidemia treatment principles are based on reducing synthesis of cholesterol. Many drugs available today are statins [10]. 
Traditional treatment principles for hyperlipidemia aim to reduce cholesterol biogenesis, which decreases blood levels of cholesterol. Statins generally act by inhibiting 3-hydroxy-3-methylgluataryl coenzyme a reductase. This enzyme helps in cholesterol biosynthesis. These drugs are most commonly used to control hyperlipidemia. Numerous studies have shown that, the treatment of Hyperlipidemia with statins, leads to chronic toxic effects which include carcinogenic, teratogenic, and mutagenic changes during longer duration of treatment. This has led to a search for more natural ways for controlling cholesterol levels [12].

Increased plasma levels of atorvastatin, lovastatin, and simvastatin may result in increased risk of severe myopathy or rhabdomyolysis [13].

So, in order to find solutions to these problems, healthcare researchers are looking for compounds with no or minimal side effects to treat hyperlipidemia. In this context, Ayurved system has the potential to treat a number of diseases with many advanced dosage forms comprised particularly of Shodhit (processed) mercury and the products contained thereof-Rasakalpa. With this background, the present research work aims to evaluate hypolipidemic activity of ayurvedic formulations arogyavardhini and zpter tablet in high fat diet (HFD) induced hyperlipidemia in wistar rats.

\section{MATERIALS AND METHODS}

\section{Drugs and chemicals}

Arogyavardhini was procured from manufacturer shree dhootapapeshwar limited; mumbai, india, zpter was procured from manufacturer, solumiks herbaceuticals; mumbai, India atorvastatin and carboxyl methyl cellulose (CMC) were procured from local market.

\section{Arogyavardhini}

Arogyavardhini is an ayurveda herbo-mineral formulation, generally used for treating affectations of liver and spleen like jaundice, ajeerna (indigestion), durdharsha-kshutprapartini (Loss of appetite) and skin diseases. It consists of tamra bhasma (processed copper), shodhit (processed) mercury, triphala, amalaki (Emblica officinalis) fruit pericarp, chitraka (Plumbago zeylanica) root, katuka (Picrorhiza kurroa) rhizome, shodhit guggulu (processed Commiphora weightii) exudate, as major ingredients processed in nimba (Azadirachta indica) leaf juice.

Zpter tablets is an ayurvedic formulation commonly indicated in the prevention and treating non-insulin dependent diabetes mellitus. Major contents of zpter tablet are asana (Pterocarpus marsupium), tvak (Cinnamomum zeylanicum), haridra (Curcuma longa), amalaki (Emblica officinalis) fruit pericarp and guduchi (Tinospora cordifolia).

\section{Preparation of doses, treatment, and duration}

The test formulations and standard drug were weighed and formulated with CMC $(1 \% \mathrm{w} / \mathrm{v})$ freshly on every day of dosing. Animals from control group were offered CMC throughout the treatment period.

\section{Experimental design}

In house bred, healthy wistar rats at Shree Dhootapapeshwar Ayurvedic Research Foundation (Reg. No. of establishment136/PO/RcBi/S/99/CPCSEA) animal house facility were used for the study (CPCSEA protocol no. SDARF/PC/2013/03). At the starting of the experiment, the animals were acclimatized for $7 \mathrm{~d}$ in laboratory conditions. The animals were housed in sterile polypropylene cages. The room temperature was maintained at $23 \pm 1{ }^{\circ} \mathrm{C}$ and animal room humidity was maintained at $55 \pm 5 \%$. Animals were provided with a $14 \mathrm{~h}$ light $/ 10 \mathrm{hr}$ dark cycle. All the procedures conducted in the experiment were reviewed by and approved by the institutional animal ethics committee. 45 wistar rats of either sex treated with HFD rich in cholesterol for $30 \mathrm{~d}$ to ensure that enough number of animals with hyperlipidemia are available. Six animals within the control group were received standard pellet. After induction of hyperlipidemia, 24 wistar rats were taken from HFT fed animals and divided into four groups (HFD control, HFD+arogyavardhini group, HFD+zpter group, and standard control group). Animals in different groups will be treated as follows:

Normal control (NC) group: A standard pellet diet offered to animals, over experimental period and was designated as NC group.

HFD control group: Animals received a cholesterol-rich HFD over experimental period and was designated as a HFD control group.

HFD+arogyavardhini group: Animals received a HFD rich in cholesterol over a period of $30 \mathrm{~d}$ and treated with arogyavardhini for the next $28 \mathrm{~d}$. HFD continued during treatment.

HFD+zpter group: Animals received a HFD rich in Cholesterol over a period of $30 \mathrm{~d}$ and treatment with zpter for the next $28 \mathrm{~d}$. HFD continued during treatment.

Standard control group: Animals received a HFD rich in Cholesterol and purified water for $30 \mathrm{~d}$ and treatment with atorvastatin as standard treatment for the 28 next days. HFD continued during treatment.

The therapeutic dose equivalent to that of human therapeutic dose for Arogyavardhini and zpter was calculated. Therapeutic dose for Arogyavardhini in Rats was $18 \mathrm{mg} / \mathrm{kg}$ body weight/day and zpter was $49 \mathrm{mg} / \mathrm{kg}$ body weight/day.

Initial body weights of animals were recorded. Body weight recording was done once every week during the experiment. Animals were treated for $28 \mathrm{~d}$ with respective group-specific agent.

\section{Serum biochemical analysis}

At the end of the experiment, blood was collected from rats in all groups by retro-orbital route. Animals were anesthetized at the time of blood collection. The serum lipid profile estimation (TC, TG, LDL, VLDL, and HDL) was carried out in automated chemistry analyzer (Randox Daytona, UK).

\section{Histopathological evaluation of liver}

Animals were humanely euthanized and liver tissue collected for histopathological evaluation. The tissue was thoroughly washed with normal saline solution and then tissue was fixed with $10 \%$ buffered formalin solution. After Fixation tissue was sliced into 4 $\mathrm{mm}$ thick slices and kept into plastic cassettes. Further tissue was immersed in paraffin and cut into 5 micrometers thin sections using a rotary microtome. Then sections were warmed and stained using hematoxylin and eosin stain. Tissue sections were examined using light microscope.

\section{Statistical analysis}

Values were represented as mean \pm standard deviations (SD) for all groups. ANOVA, followed by Tukey's post-hoc test was done to compare the difference in group means and $P<0.05$ was taken as the level of significance. Non parametric comparison with Tukey's posthoc analysis was carried out using statistical software GraphPad Prism 8.00.

\section{RESULTS}

\section{Effect of test formulation on body weight of wistar rats}

During the period of hyperlipidemia induction and treatment, measurable changes in body weight were observed. At the end of the study, HFD treated rats showed significant $(P<0.01)$ increase in body weight when compared with normal control rats. After $28 \mathrm{~d}$ treatment with test formulations, arogyavardhini $(P<0.01)$ and zpter $(P<0.05)$ treated groups of rats showed significantly decreased in the body weight when compared with HFD treated groups of rats (fig. 1). 


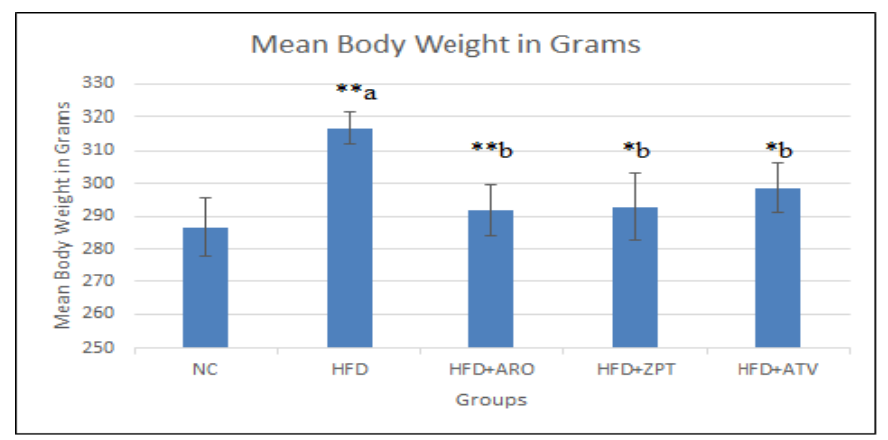

Fig. 1: Effect of test formulations on body weight in wistar rats. All data expressed as group mean \pm SD Where NC-Normal Control, HFD High Fat Diet, ARG-Arogyavardhini, ATV-Atorvastatin. Where a $\mathrm{P}=$ Vs Normal Control, $\mathrm{b} \mathrm{P}=\mathrm{Vs}$ HFD Control and $*=(\mathrm{P}<0.05), * *=(\mathrm{P}<0.01)$

\section{Effect of test formulation on lipid profile of rats}

HFD group shows significant $(\mathrm{P}<0.01)$ increase in total cholesterol (TC) levels (Group Mean $207.15 \mathrm{mg} / \mathrm{dl}$ ) when compared with standard pellet fed rats (group mean 151.05 $\mathrm{mg} / \mathrm{dl}$ ). Treatment with Arogyavardhini (group Mean=160.123) and zpter (group mean $=163.89 \mathrm{mg} / \mathrm{dl}$ ) significantly $(\mathrm{P}<0.05)$ reduces the increased level of TC in hyperlipedimic rats, which is comparable to standard treatment atorvastatin (group mean = $155.81 \mathrm{mg} / \mathrm{dl})$.

HFD group shows significant $(\mathrm{P}<0.01)$ increase in triglyceride $(\mathrm{TG})$ levels (group mean $223.83 \mathrm{mg} / \mathrm{dl}$ ) when compared with standard pellet fed rats (group mean $164.67 \mathrm{mg} / \mathrm{dl}$ ). Treatment with Arogyavardhini (group mean $=189.5 \mathrm{mg} / \mathrm{dl}$ ) and zpter (group mean $=193.16 \mathrm{mg} / \mathrm{dl})$ significantly $(\mathrm{P}<0.05)$ reduces the increased level of TG in hyperlipedimic rats, which is comparable to standard treatment atorvastatin (group mean $=180.33 \mathrm{mg} / \mathrm{dl}$ ). Fig. 2-A, 2-B).
In this study, we found that, in HFD fed group, there was significant $(\mathrm{p}<0.05, \mathrm{P}<0.01)$ increase in serum, LDL level (group mean=143.55 $\mathrm{mg} / \mathrm{dl}$ ) and VLDL levels (group mean= $44.76 \mathrm{mg} / \mathrm{dl}$ ), when compared with standard pellet treated rats (LDL group mean $=91.95$ $\mathrm{mg} / \mathrm{dl}$ and VLDL group mean $=32.93 \mathrm{mg} / \mathrm{dl}$ ). Treatment with test formulations arogyavardhini (LDL group mean= $96.05 \mathrm{mg} / \mathrm{dl}$ and VLDL group mean $=37.9 \mathrm{mg} / \mathrm{dl}$ ) and zpter $(\mathrm{LDL}$ group mean $=99.93$ $\mathrm{mg} / \mathrm{dl}$ and VLDL group mean $=38.63 \mathrm{mg} / \mathrm{dl})$ significantly $(\mathrm{p}<0.05)$ reduces elevated levels of LDL and VLDL which are comparable to that of standard treatment atorvastatin (fig. 2-D and 2-E).

In this study, HFD group rats show lower level of HDL (group mean $=18.83 \mathrm{mg} / \mathrm{dl}$ as compare to Normal control group rats (group mean=26.67 mg/dl). Whereas, treatment with test formulation arogyavardhini (group mean=26.17 mg/dl) and zpter (group mean $=25.33 \mathrm{mg} / \mathrm{dl}$ ) and standard treatment (atorvastatin-28.17) significantly $(\mathrm{p}<0.05)$ elevates the decrease level of HDL as compared to HFD treated rats (fig. 2-C).
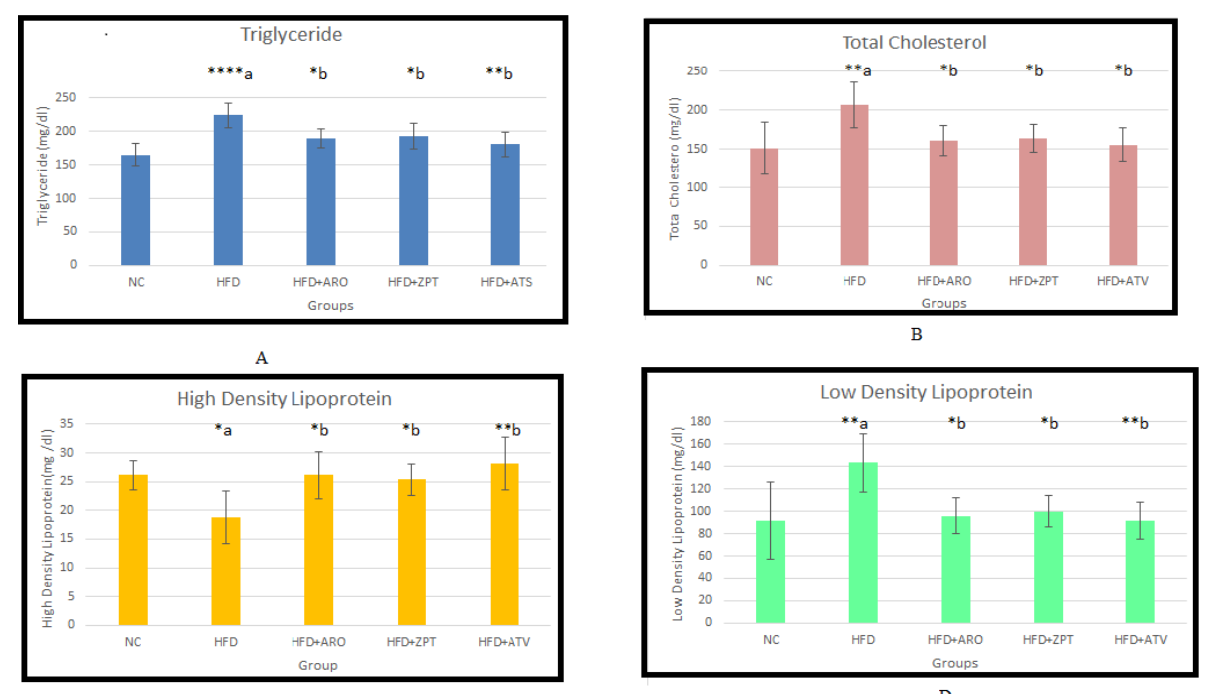

C

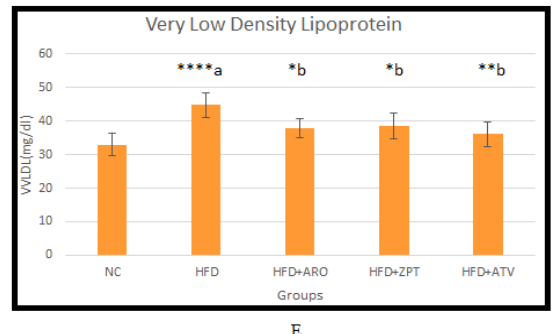

Fig. 2: Effect of test formulations on lipid profile of rats, all data expressed in mean \pm Standard deviation (SD) Where NC-normal control, HFD high fat diet, ARG-arogyavardhini, and ATV-atorvastatin. Where a $\mathrm{P}=\mathrm{Vs}$ Normal Control, $\mathrm{b} \mathbf{P}=\mathrm{Vs}$ HFD Control and $*=(\mathrm{P}<0.05)$, $* *=$

$(\mathrm{P}<0.01),{ }^{* * * *}=(\mathrm{P}<0.0001), \mathrm{n}=6,(\mathrm{~A}=$ effect of test formulation on triglyceride, $\mathrm{B}=$ effect of test formulation on total cholesterol, $\mathrm{C}=$ effect of Test formulation on HDL, $D=$ effect of test formulation on LDL, $E=$ effect of test formulation on VLDL) 
Histology by hematoxylin and eosin ( $\mathrm{H}$ and $\mathrm{E}$ ) staining of rat liver section shows lipid droplet accumulation with the change in hepatocyte architecture in HFD fed control group of rats (fig. 3 B). Treatment with test formulations arogyavardhini and zpter group shows decrease in lipid droplet accumulation compared to HFD control group of rats and regaining of normal architecture (fig. 3-C, 3 D).

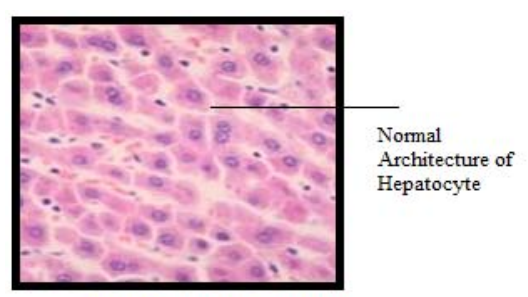

3A- NC (Nomal Control)

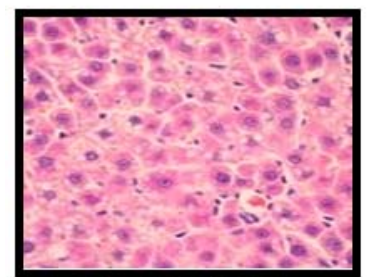

3 C-HFD + ARG
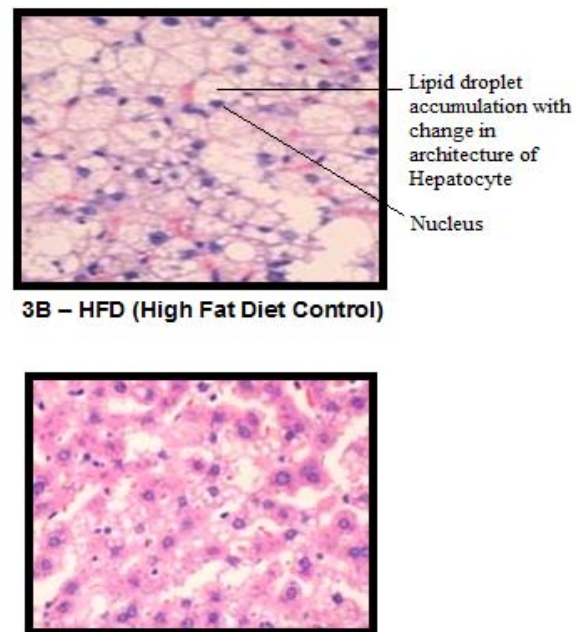

3 D HFD + ZPT

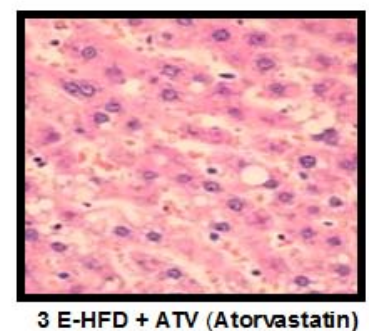

Fig. 3: Histology of rats liver tissue (H and $\mathrm{E}$ staining) with $10 \mathrm{x}$ magnification, where $3 \mathrm{~A}=$ liver histology from $\mathrm{NC}$ (Normal Control) group, 3 B HFD = Liver Histology from HFD control group, 3C HFD+ARG = Liver Histology from arogyavardhini treated group 3D HFD+ZPT = Liver Histology from Zpter treated group, 3E HFD+ATV = liver histology from atorvastatin treated group

\section{DISCUSSION}

Joris et al. reported that cholesterol alone cannot induce hyperlipidemia in Rats, so cholic acid is added with dietary cholesterol in order to induce hyperlipidemia [12]. The high fat diet administered in the present study includes cholic acid for effective hyperlipidemia induction $[14,15]$.

The significant increase in serum TG and TC particularly, LDL and VLDL indicate induction of hyperlipidemia which further leads to the development of atherosclerosis.

In humans, statin drugs are commonly used as cholesterol-lowering drugs. Therefore, the standard group was used to measure the effectiveness of the ayurvedic formulations in reducing plasma cholesterol levels when compared with statins $[16,17]$.

Findings in our study showed significant $(p<0.05)$ increase in serum TG, TC, LDL and VLDL and significant $(\mathrm{p}<0.05)$ decrease in HDL group when compared with standard pellet fed rats. Findings in our study are Similar to those of previous reports, which confirms the induction of hyperlipidemia [15-19].

Increase in serum LDL level causes cholesterol deposition in the arteries and aorta which further causes CHD as LDL involved in transport of cholesterol from the liver to end arteries [20, 21]. HDL, a lipoprotein synthesized in intestine and liver protect the system from the adverse effects of atherosclerosis [22].

Treatment with test formulation (arogyavardhini and zpter) and standard treatment (atorvastatin) significantly $(\mathrm{p}<0.05)$ reduces the increased level of TG and cholesterol particularly LDL, VLDL in hyperlipidemic rats. Treatment with test formulation (Arogyavardhini and zpter) and standard treatment (Atorvastatin) significantly $(p<0.05)$ elevates the decrease level of HDL in hyperlipedimic rats. The finding of our study represents similarities with the previous outcome [15].

The decrease in serum TC, LDL, TG, and increased HDL levels with arogyavardhini vati was reported previously in an efficacy study [23]. Guduchi (Tinospora cordifolia), which is major component of zpter Tablet has been reported to decrease triglyceride level in blood [24]. Extract of Curcuma longa which is component of zpter tablet was reported to shown a decrease in total plasma cholesterol and low-density lipoprotein cholesterol but increase in high-density lipoprotein cholesterol in rats fed with high-cholesterol diet [25]. Histopathological examination of liver tissues shown the decrease in fatty cytoplasm filled vacuolated cells in liver parenchyma with a decrease in hepatic necrosis and tissue architecture was coming back to normal. All the results obtained in our study are supported by previous findings.

\section{CONCLUSION}

The present investigation showed that arogyavardhini and zpter reduce the elevated level of serum TC, TG, LDL and VLDL and efficacies are comparable to that of standard treatment Atorvastatin. Treatment with test formulations arogyavardhini, zpter, and standard treatment atorvastatin prevent reduction of serum HDL level. Both test formulations arogyavardhini and zpter have the comparable hypolipidemic activity to standard treatment atorvastatin. From these findings indicate that Arogyavardhini and zpter have potential to treat Hyperlipidemia and in other associated disorders such as atherosclerosis.

\section{AUTHORS CONTRIBUTIONS}

Dr. Dinesh D. Ghadigaonkar:-Veterinarian involved in experiment, 
supervision and guidance for dosing in lab animals, blood sample collection from animal's and conducting veterinary examination and health checkup of animal before study initiation and during study. Manuscript writing, submission.

Mukesh B Chawda:-Basic concept for research, Ayurvedic Physician to decide dose, route of herbal formulation and guiding about selection of dose duration for ayurvedic formulation.

Kapil S Thakur:-Providing expert supervision specifically about quality aspect of choosing herbal formulations and controlling quality during production of herbal formulation and controlling quality check for procedures in the experiment.

Mr. Pawan Kushwah: involve in technical aspect in experiment like dosing of animals, body weight measurement data collection and recording.

\section{CONFLICT OF INTERESTS}

There is no conflict of interest exist

\section{REFERENCES}

1. Chen HZ. Current status of blood lipid level and treatment of hyperlipoidemia in Chinese population. J Chin Integr Med 2004;2 Suppl 2:81-2.

2. Mishra PR, Panda PK, Apanna KC, Panigrahi S. Evaluation of acute hypolipidemic activity of different plant extracts in triton WR-1339 induced hyperlipidemia in albino rats. Pharmacologyonline 2011;3:925-34.

3. Jeyabalan S, Palayan M. Antihyperlipidemic activity of sapindusemarginatus in triton WR-1339 induced albino rats. Res J Pharm Tech 2009;2:319-23.

4. Marek Iannucci S, Taylor D, Thomas A, Tucker K, Andres A, Czer LS, et al. Hyperlipidemia impairs autophagy in chronic heart failure. J Heart Lung Transplant 2018;37:S233.

5. Yusuf S, Hawken S, Ounpuu S, Dans T, Avezum A, Lanas F, et al. Effect of potentially modifiable risk factors associated with myocardial infarction in 52 countries (the INTERHEART study): case-control study. Lancet 2004;364:937-52.

6. Ference BA, Ginsberg HN, Graham I, Ray KK, Packard CJ, Bruckert E, et al. Low-density lipoproteins cause atherosclerotic cardiovascular disease. Evidence from genetic, epidemiologic, and clinical studies. A consensus statement from the european atherosclerosis society consensus panel. Eur Heart J 2017;38:2459-72.

7. Ranjan N. Management of hyperlipidemia: an update. Indian J Dermatol Venereol Leprol 2009;75:452-62.

8. World Health Organisation [Internet] Global Health observatory (GHO) data. Available from: http://www.who.int/ gho/ncd/risk_factors/cholesterol_text/en/. [Last accessed on 10 Oct 2018].

9. Kizhakkeveettil A, Jayagopal PS, Rose K. Hypercholesterolemia and ayurvedic medicine: a case report. Topics Integrative Health Care 2011;2:2006.
10. Verma N. Introduction to hyperlipidemia and its treatment: a review. Int J Curr Pharm Res 2017;9:6-14.

11. Manjiri AN, Vyas SN, Baghel MS, Ravishankar B. Randomized placebo controlled trial of mustadi ghanavati in hyperlipidemia. AYU 2010;31:287-93.

12. Joris IZ, Nunnari JJ, Krolikowski FJ, Majno G. Studies on the pathogenesis of atherosclerosis adhesion and emigration of mononuclear cells in the aorta of hypercholesterolemic rats. Am J Pathol 1983;113:341-58.

13. Golomb BA, Evans M. Statin adverse effects: a review of the literature and evidence for a mitochondrial mechanism. Am J Cardiovasc Drugs 2008;8:373-418.

14. Guido S, Joesph T. Effect of chemically different antagonists on lipid profile in rat fed on a high fat diet. Indian J Exp Biol 1992;30:292-4.

15. Shaik J, Khan Z. Antihyperlipidemic activity of Commiphora mukul against atherogenic diet-induced hyperlipidemia in experimental rats. Asian J Pharm Clin Res 2018;11:386-9.

16. Sravanthi P, Shakir Basha S. Anti-atherosclerotic activity of ethanolic extract of chrysanthemum indicum flowers against high-fat diet-induced atherosclerosis in male wistar rats. Asian J Pharm Clin Res 2017;10:52-6.

17. Chen C, Liu L, Hsu J, Huang H, Yang M, Wang C. Mulberry extract inhibits the development of atherosclerosis in cholesterol-fed-rabbits. Food Chem 2005;91:601-7.

18. Rauch U, Osende JJ, Chasebro JH, Fuster V, Vorchheimer DA, Harris K, et al. Statin and cardiovascular disease: The multiple effects of lipid-lowering therapy by statin. Atherosclerosis 2002;153:181-9.

19. Rosenson RS. Statins in atherosclerosis. Atherosclerosis 2004;173:1-12.

20. Boden WE, Pearson TA. Raising low levels of high-density lipoprotein cholesterol is an important target of therapy. Am J Cardiol 2000;85:645-50.

21. Pedersen TR. Low density lipoprotein cholesterol lowering is and will be the key to the future of lipid management. Am J Cardiol 2001;87:8B-12B.

22. $\mathrm{Xu} \mathrm{Y}, \mathrm{He} \mathrm{Z}$, King GL. Introduction of hyperglycemia and dyslipidemia in the pathogenesis of diabetic vascular complications. Curr Diab Rep 2005;5:91-7.

23. Kumar G, Srivastava A, Sharma SK, Gupta YK. Safety and efficacy evaluation of ayurvedic treatment (Arjuna powder and Arogyavardhini Vati) in dyslipidemia patients: a pilot prospective cohort clinical study. Ayu 2012;33:197-201.

24. Reddy SS, Ramatholisamma P, Karunaa R, Saralakumari D. Preventive effect of Tinospora cordifolia against high-fructose diet-induced insulin resistance and oxidative stress in male wistar rats. Food Chem Toxicol 2009;47:2224-9.

25. Wing FY, Kwan PL, Wong CY, Kam TS, Chiu SM,Chan SW, et al. Attenuation of fatty liver and prevention of hypercholesterolemia by extract of Curcuma longa through regulating the expression of CYP7A1, LDL Receptor, HO-1, and HMG-CoA reductase. J Food Sci 2011;76:H80-9. 